\title{
EFFECT OF PLATELET RICH PLASMA-ENRICHED GELFOAM ON CHRONIC TYMPANIC MEMBRANE PERFORATION
}

\author{
By \\ Ahmed Seddik Abd El-Gelil and Yahia Mohamed Dawod \\ Otorhinolaryngology Department, Faculty of Medicine, Al-Azhar University \\ E-mail: Dr_ahmedseddik@yahoo.com - Yahia_24@yahoo.com
}

\begin{abstract}
Background: Tympanic Membrane (TM) perforation is one of the common reasons of patients' attending Otolaryngology clinics. Repair of tympanic membrane perforations with most accepted techniques reaches a success rate of over 90\%. Platelet-Rich Plasma (PRP) can be defined as an autologous concentration of human platelets in a small volume of plasma.

Objective: The aim of this study was to evaluate the effect of PRP-enriched gel foam on the healing of chronic TM perforation in comparison with gel foam alone after myringoplasty.

Patients and Methods: In this double-blind randomized clinical trial, 40 patients with chronic tympanic membrane perforations, attending the ENT outpatient clinics of Al-Azhar university hospitals between September, 2017 and May, 2019, they were randomly allocated to two groups; intervention group, underwent myringoplasty with platelet rich plasma (PRP)-enriched gel foams and control group, underwent myringoplasty operation with conventional gel foams alone. Patients were seen 1 month, 3 months and 6 months after surgery.

Results: Forty patients, 21 males (52.5\%) and 19 females (47.5\%) with a mean age of $45.3 \pm 11.9$ years in intervention, and $43.98 \pm 10.8$ years in control group underwent analysis. Complete TM healing was seen in $19(95 \%)$ patients in intervention group, and $14(70 \%)$ patients in control group three months after intervention. No complications were seen in intervention group, while three otorrhea cases were recorded for control group in the first follow up after intervention which was resolved by medication.
\end{abstract}

Conclusion: Addition of PRP to conventional gel foams used in TM perforation repair increased the complete healing rate of TM perforation to a significant extent.

Key Words: Platelet-rich plasma, gel foam, tympanic membrane perforation.

\section{INTRODUCTION}

Myringoplasty is considered the most effective and reliable method of repairing tympanic membrane perforations. It has been used with various surgical techniques, and with numerous grafting materials to reconstruct the TM, including; skin, fascia, cartilage, vein, fat, perichondrium and dura mater. Temporalis facia is considered by most surgeons to be the material of choice for myringoplasty (Akbar and Saif, 2019).

Various agents such as hyaluronic acid, pentoxifylline and fibroblast growth factors have been tried to aid the healing of tympanic membrane perforations (Habesogl et al., 2014).

The use of PRP has gained popularity with application in many medical fields such as cosmetic surgery, dentistry, pain 
management, craniofacial, orthopedic, neurological surgery and sports medicine (Maria et al., 2011).

Platelet-rich plasma (PRP) is the part of the blood plasma derived from a small volume of whole blood subjected to a special centrifugation procedure, and it contains a high concentration of platelets. After it has been activated, growth factors are present with the de-granulation of the platelets, and the process of wound healing begins. These growth factors include platelet-derived growth factor (PDGF), insulin-like growth factor (IGF), and vascular endothelial growth factor (VEGF) (Cervelli et al., 2009).

Myringoplasty refers to simple surgical closure of a perforation in tympanic membrane without ossicular reconstruction. Platelet rich plasma (PRP) with various growth factors has been proved to improve wound healing. PRP has been used with myringoplasty procedures to aid healing of tympanic membrane perforation by many surgeons. Erkilet et al. (2009) reported that autologous platelet rich plasma (PRP) effectively accelerated tympanic membrane perforation in rats. El-Anwar et al. (2015) demonstrated a positive effect of PRP on healing of large tympanic membrane perforations.

The aim of this study was to evaluate the effect of PRP-enriched gel foam on the healing of chronic TM perforation, in comparison with gel foam alone in myringoplasty.

\section{PATIENTS AND METHODS}

This prospective double-blind randomized clinical trial included forty patients, selected from the Outpatient
Clinics of ENT Department, Faculty of Medicine, ALAZHAR University Hospitals, during the period between September, 2017 and May, 2019. The study protocol was approved by the institutional ethical review committee. Informed consents were obtained from all patients.

Patients were randomly allocated into two groups; PRP group, (20 patients) underwent myringoplasty with platelet rich plasma (PRP)-enriched gel foam and a control group, (20 patients) underwent myringoplasty operation with conventional gel foam alone.

\section{Inclusion criteria:}

- Patients between 18 and 60 years of age, representing both genders.

- Patients had central tympanic membrane perforations (all sizes), without cholesteatoma or ossicular discontinuity.

- All ears must be dry for at least a month before surgery.

\section{Exclusion criteria:}

- Patients with active otorrhea, cholesteatoma, canal stenosis, marginal perforation, autoimmune and hematologic diseases, active neoplasm, immunosuppressive treatment and diabetes.

- Previously operated ears.

\section{All patients were subjected to:}

- Complete history taking; including History of past ventilation tube, allergic and asthmatic tendencies, if the patient undergone tympanic membrane surgery on the same ear previously and history of a bleeding tendency. 
- Clinical examination; including nose and nasopharynx.

- Thorough ear examination; including otoscopic and microscopic ear examination to confirm diagnosis and exclude other pathologies.

- Routine audiological assessment; pure tone audiometry, done before and 3 months after surgery.

\section{Statistical Analysis:}

The collected data were tabulated and statistically analyzed using SPSS program (Statistical Package for Social Sciences) software version 20.0 (SPSS Inc., Chicago, Illinois, USA). Inferential analyses were done for qualitative data using Chi square test for independent groups.

\section{RESULTS}

A total of 40 patients, $21(52.5 \%)$ males and $19(47.5 \%)$ females, with a mean age of $45.3 \pm 11.9$ years in PRP group, and $43.98 \pm 10.8$ years in the control group, underwent analysis. In PRP group 9 $(45 \%)$ and in control group $10(50 \%)$ patients had underlying diseases like hypertension, dyslipidemia, hypothyroidism and diabetes mellitus. There was no significant difference for underlying disease between two groups. In PRP group, $12(60 \%)$ right and $8(40 \%)$ left and in control group $13(65 \%)$ right and $7(35 \%)$ left ears were enrolled (Table 1).

Table (1): Baseline data of the studied groups

\begin{tabular}{|c|c|c|c|}
\hline $\begin{array}{ll}\text { Parameters } & \text { Groups }\end{array}$ & $\begin{array}{l}\text { Control } \\
(\mathrm{n}=20)\end{array}$ & $\begin{array}{l}\text { PRP group } \\
(\mathrm{n}=20)\end{array}$ & $\mathrm{p}$ \\
\hline Age (years) & $43.98 \pm 10.8$ & $45.3 \pm 11.9$ & 0.72 \\
\hline $\begin{array}{l}\text { Gender } \\
\text { Male } \\
\text { Female }\end{array}$ & $\begin{array}{l}10(50 \%) \\
10(50 \%)\end{array}$ & $\begin{array}{c}11(55 \%) \\
9(45 \%)\end{array}$ & 0.75 \\
\hline $\begin{array}{c}\text { Side of TM rupture } \\
\text { Right } \\
\text { Left }\end{array}$ & $\begin{array}{c}13(65 \%) \\
7(35 \%)\end{array}$ & $\begin{array}{l}12(60 \%) \\
8(40 \%)\end{array}$ & 0.74 \\
\hline $\begin{array}{l}\text { Underlying diseases } \\
\text { Hypertension } \\
\text { Dyslipidemia } \\
\text { Hypothyroidism } \\
\text { Diabetes mellitus }\end{array}$ & $\begin{array}{c}4(20 \%) \\
2(10 \%) \\
1(5 \%) \\
3(15 \%)\end{array}$ & $\begin{array}{c}5(25 \%) \\
1(5 \%) \\
1(5 \%) \\
2(10 \%)\end{array}$ & 0.9 \\
\hline
\end{tabular}

Complete TM healing was seen in 19 (90\%) patients in PRP group, and 14 $(70 \%)$ patients in control group three months after intervention, none of the patients developed hearing impairment, tinnitus, vertigo or bleeding, apart from three otorrhea cases were recorded for control group in the first follow up after intervention which were resolved by medication (Table 2). 
Table (2): Outcome measures

\begin{tabular}{|c|c|c|c|c|c|}
\hline \multirow{2}{*}{ Groups } & \multicolumn{2}{|c|}{$\begin{array}{c}\text { Control } \\
(\mathrm{n}=20)\end{array}$} & \multicolumn{2}{c|}{$\begin{array}{c}\text { PRP group } \\
(\mathrm{n}=20)\end{array}$} & \multirow{2}{*}{$\mathrm{p}$} \\
\cline { 2 - 5 } Parameters & No & $\%$ & No & $\%$ & \\
\hline $\begin{array}{c}\text { Complete TM } \\
\text { healing }\end{array}$ & $\mathbf{1 4}$ & $\mathbf{7 0}$ & $\mathbf{1 9}$ & $\mathbf{9 5}$ & $\mathbf{0 . 0 4 5}$ \\
\hline
\end{tabular}

\section{DISCUSSION}

Myringoplasty involves repair of tympanic membrane perforation with an autologous graft. Habesoglu et al., (2014) proved in their study that growth accelerators like hyaluronic acid, pentoxifylline, basic fibroblast growth factor (bFGF) and epidermal growth factor are the most promising agents in terms of rapid TM closure, when applied with the graft material.

Since the above mentioned growth factors are not strictly autologous, expensive and require biochemical handling of blood, there was a need to develop an alternative which is easy, quick, cheap and biocompatible (Garin et al., 2014).

PRP is an autologous concentrate of human platelets in a small volume of plasma containing biologically active factors responsible for hemostasis, synthesis of new connective tissue and revascularization (Sommeling et al., 2013).

PRP, when activated, can release multiple growth factors, including connective tissue growth factor (CTGF), fibroblastic growth factor-2 (FGF-2), bone morphogenetic protein (BMP-2), and transforming growth factor-beta 2 (TGF32). These multiple growth factors released from PRP may play a synergistic role in the cell proliferation (Tang et al., 2015).
It has also been shown that due to the presence of WBCs, PRP grafts are bactericidal (Tate and Crane, 2010).

The application of PRP in otolaryngology and facial plastic surgery is widespread, and includes; ear surgery [myringoplasty (El-Anwar et al., 2015) and posterior meatal wall reconstruction (Mohammad et al., 2018) nose surgery [rhinoplasty (Dhafer, 2016), endoscopic sinus surgery (Mohebbi et al., 2018) and treating anosmia (Panayiota et al., 2016)], laryngeal and vocal cord surgery (Serap et al., 2016), promotion of wound healing in superficial parotidectomy (Scala et al., 2014).

The use of PRP with myringoplasty has been tried by many researchers and in different ways;

El-Anwar et al. (2015) used autologous PRP with conchal perichondrial grafts for tympanic membrane perforations in a group of patients with success rate (graft taking) $100 \%$ while in the control group with no PRP application, (graft taking) was $81.25 \%$. Infection rate in control group was found to be significantly higher than in case group.

Ahmed et al. (2018) used PRP with fat myringoplasty in twenty patients with small to medium sized tympanic membrane perforations, $100 \%$ success rate was obtained in small perforation and $79.3 \%$ in medium sized perforation. 
Tamer et al., (2018) carried out fat graft myringoplasty in forty patients with dry central tympanic membrane perforations. Half the patients with PRP application (group A), while others served as control and received the fat graft only without PRP (group B). success rate was $(90 \%)$ in (group A), while (55\%) in (group B).

Ruta et al. (2018) in their study on 20 patients with inactive central tympanic membrane perforation, performed an underlay myringoplasty using temporalis facia, autologous PRP was applied into external auditory canal over the surface of the graft and tympanic membrane remnant, success rate was $100 \%$ of cases.

Gel foam enriched with PRP has been used by Saeedi et al. (2017) as a gel foam plug.

The aim of this study was to evaluate the effect of PRP on the healing of chronic TM perforation using PRP-enriched gel foam in comparison with gel foam alone, we performed myringoplasty using temporalis facia, underlay technique. Complete TM healing was seen in 95\% patients in PRP group and in $70 \%$ of patients in control group three months after intervention. Our results were in agreement with Yadav et al. (2018) where graft uptake was $95 \%$ in intervention group and $85 \%$ in the control group.

In our study, no reported postoperative infection in PRP group, while three otorrhea cases were recorded for control group in the first follow up after intervention, this was in agreement with Saeedi et al. (2017) who recorded no morbidities for PRP group. Also, ElAnwar et al. (2015) reported that infection rate in control group was found to be significantly higher than in PRP group.
The present study has a relatively low sample size; so further studies with a larger sample size are suggested for certain conclusion about effects of PRP in TM repair.

\section{CONCLUSION}

Addition of PRP to conventional gel foams used in TM perforation repair increases the complete healing rates to a significant extent. Also, using PRP was associated with less morbidity and postoperational complications.

\section{REFERENCES}

1. Ahmed R., Yasser A., Magdy B. and Saeed A. (2018): Myringoplasty Of Central Tympanic Membrane Perforation With A Fat Graft From The Ear Lobule And Platelet Rich Plasma. Z.U.M.J., 24: (2): 188-192.

2. Akbar Z. and Saif O. (2019): Myringoplasty using temporalis fascia and its clinical outcome. Int J Otorhinolaryngol Head Neck Surg., 5:1539-42.

3. Cervelli V., Gentile P., Scioli M. and Grimaldi M. (2009): Application of plateletrich plasma in plastic surgery: clinical and in vitro evaluation. Tissue Eng Part C Methods, 15:625-34.

4. Dhafer A. (2016): Use of PRP in Rhinoplasty. Otolaryngol (Sunnyvale), 6(6):280-282.

5. El-Anwar M., El-ahl M., Zidan A. and Yacoup M. (2015): Topical use of autologous Platelet rich plasma in myringolplasty. Arius Nasus Larynx, 42(5):365-8.

6. Erkilet E., Koyuncu M., Atmaca S. and Yarim M. (2009): Platelet rich plasma improves healing of tympanic membrane perforations: Expermental study. J Laryngol Otol., 123(5):482-7.

7. Fawzy T., Hussein M., Eid S. and Guindi S. (2018): Effect of adding platelet-rich plasma to fat grafts in myringoplasty. Egypt J Otolaryngol, 34;224-8. 
8. Garin P., Peerbaccus Y., Mardyla N., Mullier F., Gheldof $D$. and Dogne J. (2014): Platelet-Rich plasma (PRP): an autologous packing material for middle ear microsurgery. B-ENT, 10:27-34.

9. Habesoglu M., Oysu C., Yilmaz A. and Tosun A. (2014): Platelet rich fibrin for repair of tympanic membrane. J Craniofac Surg., 25(6):2056-8.

10. Maria L., Ortiz L., Rodriguez R. and Boemo J. (2011): Research Article on Pilot Study on the Efficiency of the Biostimulation with Autologous Plasma Rich in Platelet Growth Factors in Otorhinolaryngology: Otologic Surgery (Tympanoplasty Type I). ISRN Surgery, 7(4):213-220.

11. Mohammad A., Wail F. and Samir S. (2018): Platelet-Rich Plasma in Reconstruction of Posterior Meatal Wall after Canal Wall Down Mastoidectomy. Arch Otorhinolaryngol., 22(2):103-107.

12. Mohebbi S., Daneshi A. and Ebrahimnijad S. (2018): Evaluation of Locally Administered Autologous Platelet Rich Plasma in Reducing Symptoms of Recurrent Sinonasal Polyposis Following Endoscopic Sinus Surgery. RJMS, 25(8):24-32.

13. Panayiota M., Angelos K., Stephanie M., Samir M., Magdolna K. and Agnes S. (2016): Anosmia treatment by platelet rich plasma injection.The International Tinnitus Journal, 20(2):102-105.

14. Ruta S., Yoganathan G. and Vellavedu U. (2018): Myringoplasty with Autologous Platelet Rich Plasma -A Prospective Study. JMSCR, 10(6): 1170-1173.

15. Saeedi M., Ajalloueian M., Zare E., Taheri A., Yousefi J. and Mirlohi S. (2017): The effect of PRP-enriched gel foam on chronic tympanic membrane perforation: A doubleblind randomized clinical trial. International Tinnitus Journal, 21(2):108-111.

16. Scala M., Mereu P. and Spagnolo F. (2014): The use of platelet-rich plasma gel in patients with mixed tumor undergoing superficial parotidectomy: a randomized study. In vivo. Acta Otorhinolaryngologica Italica, 28: 121-4.

17. Serap B., Selcuk D., Hasan E., Tahsin M., Mustafa C. and Cagdas E. (2014): Treatment of Acute Vocal Fold Injury with Platelet-Rich Plasma. Journal of Voice, 30(6): 731-735.

18. Sommeling C., Heyneman A. and Hoeksema A. (2013): The use of platelet rich plasma in plastic surgery; a systematic review. An international journal of surgical reconstruction. JPRAS, 66(3):301-311.

19. Tamer F., Hussein M., Eid S. and Guindi S. (2018): Effect of adding platelet-rich plasma to fat grafts in myringoplasty. Egypt $\mathbf{J}$ Otolaryngol. 34:224-8.

20. Tang X., Dong P., Wang J., Zhou H., Zhang H. and Wang S. (2015): Effect of autologous platelet-rich plasma on the chondrogenic differentiation of rabbit adipose-derived stem cells in vitro. Exp Ther Med., 10(2):477-83.

21. Tate K. and Crane D. (2010): Platelet rich plasma grafts in musculoskeletal medicine. J Prolother., 2:371-6.

22. Yadav S., Malik J., Malik P. and Sehgal P. (2018): Studying the result of underlay myringoplasty using platelet-rich plasma. Journal of Laryngology \& Otology, 132(11):990-994. 
تأثير جيل فوم المخصب بالصفائح الدموية الغنية بالبلازما

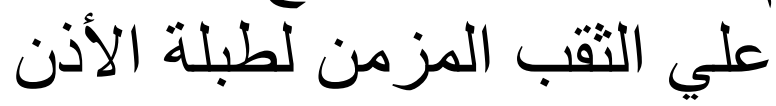
أحمد صديث عبدالجليل، يحيي محمد داود قسم الأذن والأنف والحنجرة-كلية الطب، جامعة الأزهر

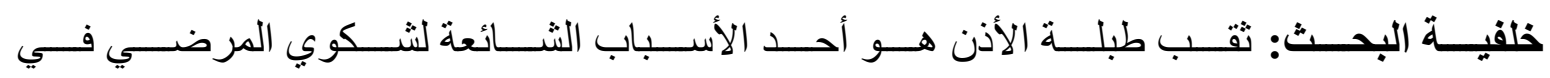

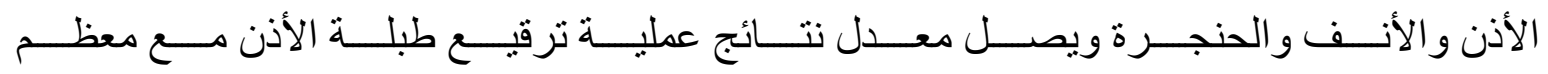

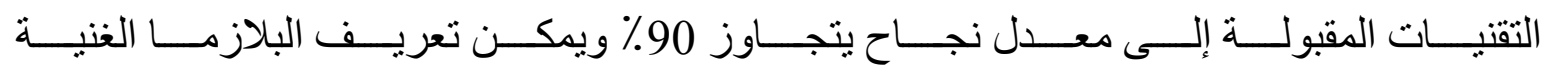

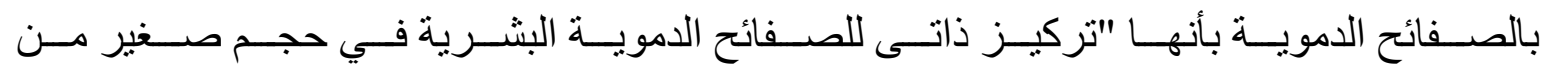
البلازما".

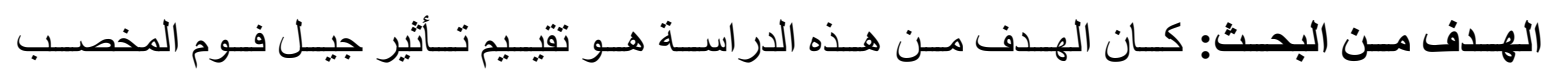
علي شفاء ثقب الطبلة المزمن بالمقارنة مع الجيل فوم وحده بعد ترقيع طبلة الأذن.

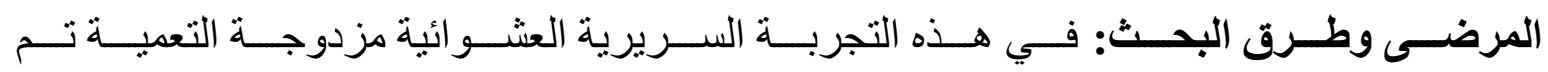

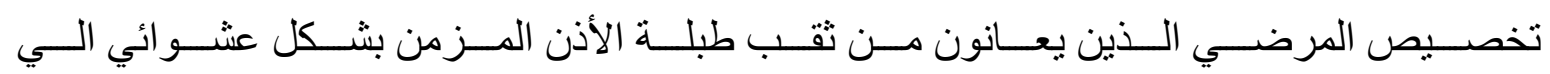

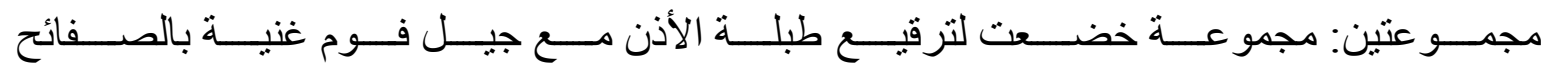

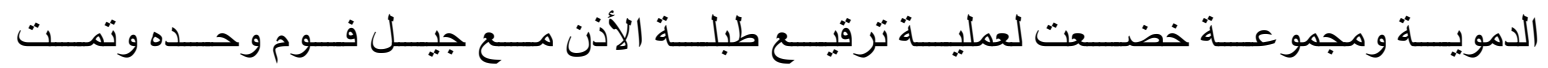
مناظرة المرضى بعد 1 شهر و 3 أشهر و 6 أشهر من الجراحة.

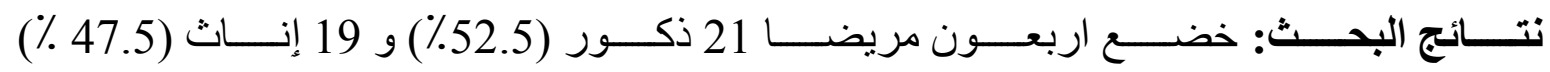

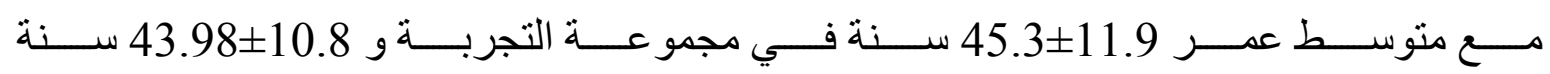

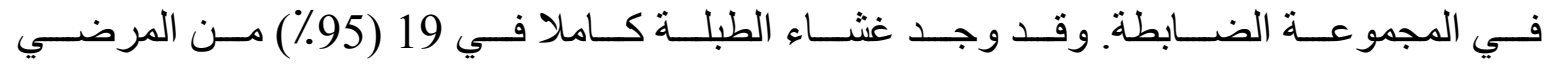

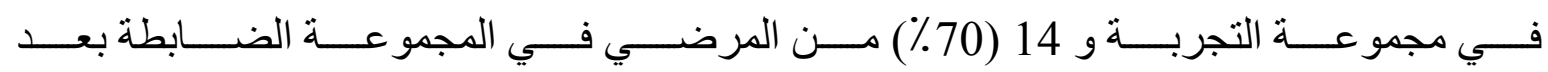

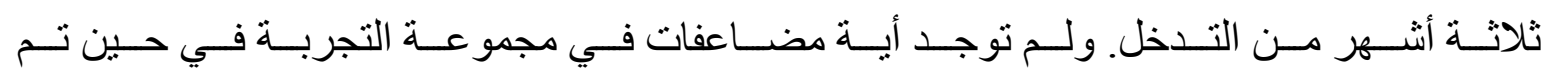
تسجيل ثلاث حالات من سيلان الأذن للمجمو عة الضابطة في المتابعة الأولي.

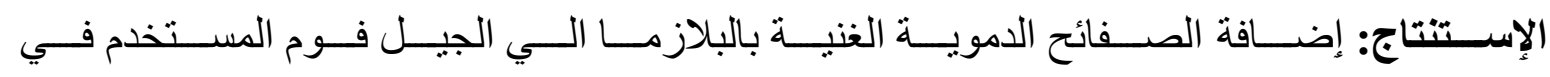
إصلاح ثقب غشاء طبلة الأذن يزيد معدل الثفاء الكامل لتقوب طبلة الأذن. 